\title{
DNA flow cytometric evaluation of cell cycle distribution in ulcerative colitis: a proposed method for assessing severity of disease
}

\author{
F Bortoluzzi, M Valentini, C Cernigoi, G Toffoli, M Boiocchi, M Poletti, M Sozzi, \\ M Fornasarig, R Cannizzaro, E Bertolissi
}

\begin{abstract}
The assessment of disease severity in ulcerative colitis depends mainly on subjective variables, and an objective method of assessing mucosal inflammation is needed. Determination of the synthetic phase of the cell cycle is an accurate expression of inflammatory activity in the colonic mucosa. The aim of the study was to find out if the proliferative index or the synthetic phase (S phase) of the colonic mucosa of patients with ulcerative colitis, as evaluated by DNA flow cytometry, is a reliable and reproducible marker of disease activity. Sixty consecutive patients with ulcerative colitis of different degrees of activity were entered into the study and submitted to colonoscopy plus multiple rectal biopsies. Disease severity was defined for each patient by means of a clinical, endoscopic, and histological score. Flow cytometry was used to calculate the proliferative index and the $S$ phase of the cell cycle. A statistically significant correlation $(p<0.001)$ was found between all indices of severity. It is suggested that flow cytometric evaluation of the cell cycle in the rectal mucosa may be an efficient method of assessing severity of disease and efficacy of medical treatment in ulcerative colitis.

(Gut 1995; 36: 50-54)
\end{abstract}

Keywords: ulcerative colitis, disease severity, DNA flow cytometry, cell cycle, proliferative index.

Division of

Gastroenterology and

Digestive Endoscopy

F Bortoluzzi

$M$ Valentini

C Cernigoi

M Poletti

M Sozzi

M Fornasarig

R Cannizzaro

E Bertolissi

and Division of

Experimental

Oncology, Regional

Cancer Centre,

Aviano, Italy

G Toffoli

M Boiocchi

Correspondence to: Dr M Valentini

Division of Gastroenterology

and Digestive Endoscopy,

and Digestive Endoscopy,

Regional Cancer Centre

CRO), Via Pedemontana

Occidentale, 33081 Avian

(PN), Italy.

Accepted for publication

12 April 1994

The assessment of disease activity in ulcerative colitis is an important factor in determining the treatment, management, and prognosis of the patients, in routine clinical use as well as in randomised trials. Clinical criteria, individual laboratory indices, endoscopic criteria, and activity indices have been proposed to quantify the severity of disease. Furthermore, indices are subject to very substantial intra and interobserver variation. Despite the many efforts made to introduce more reproducible and objective variables, the old Truelove and $\mathrm{Witts}^{1}$ index is still preferred in practical use, but is perhaps not sensitive enough for clinical trials. ${ }^{2}$ The determination of cell cycle distribution and the evaluation of the proliferative index of the colonic mucosa have been validated as having biological significance in other diseases of the colon. ${ }^{3}$ The amount of inflammatory cells determined histologically in the colonic mucosa, seems to be of prognostic importance 4 and is certainly capable of influencing the cell proliferation rate of the entire mucosa. The aim of our study was to find out if the proliferative index or the synthetic phase ( $S$ phase) of the colonic mucosa, as evaluated by DNA flow cytometry, may be a reliable and reproducible marker of disease activity in patients with ulcerative colitis.

\section{Methods}

Sixty consecutive patients (34 males, 26 females, median age 38.6 years; age range 19-62) with ulcerative colitis of different degrees of activity and receiving different treatment courses were entered into the study. The patients participated in a precancerous surveillance protocol based on histological examination and flow cytometry, irrespective of duration of illness. Each patient was submitted to diagnostic colonoscopy, and mucosal biopsy specimens were taken by biopsy forceps at various anatomical sites in the colon (caecum, ascending colon, hepatic flexure, transverse colon, splenic flexure, descending colon, sigmoid colon, and rectum). Twenty non-consecutive patients complaining of active ulcerative colitis were also submitted to a subsequent endoscopic examination after a course of medical treatment. For the purposes of this study we considered only the most distal rectal biopsy specimens: a couple of samples were taken in the rectum from adjacent sites of the mucosa. One sample from each pair was fixed in Bouin's solution for histological examination and the other immediately put in saline and submitted to flow cytometric analysis. At the same time we scored clinical and endoscopic severity of disease.

Clinical activity was determined using a semi-quantitative index, according to Rachmilewitz, ${ }^{5}$ as shown in Table 1.

The endoscopic appearance of the rectal mucosa was defined by one of four experienced endoscopists on a scale of 1-4 as suggested by Gomes et $a l^{6}$ : on this scale, 1 was normal, 2 mild inflammation with loss of vascular pattern, 3 severe inflammation with contact bleeding, and 4 severe disease with friability, ulcers or spontaneous bleeding.

The histological grade of inflammation was assessed by a single expert histopathologist who was unaware of the endoscopic severity. We also assessed histological activity according to Gomes on a 1-5 scale: 1 was normal, 2 was defined as mild oedema and inflammation 
TABLE I Clinical activity index

\begin{tabular}{|c|c|c|}
\hline & & Score \\
\hline Numbers of stools (per week) & $\begin{array}{l}<18 \\
18-35 \\
36-60 \\
>60\end{array}$ & $\begin{array}{l}0 \\
1 \\
2 \\
3\end{array}$ \\
\hline Blood in stools (weekly average) & $\begin{array}{l}\text { none } \\
\text { little } \\
\text { a lot }\end{array}$ & $\begin{array}{l}0 \\
2 \\
4\end{array}$ \\
\hline Global symptomatic state & $\begin{array}{l}\text { good } \\
\text { average } \\
\text { bad } \\
\text { very bad }\end{array}$ & $\begin{array}{l}\mathbf{1} \\
0 \\
1 \\
2 \\
3\end{array}$ \\
\hline Abdominal pain or cramps & $\begin{array}{l}\text { none } \\
\text { seldom or mild } \\
\text { severe } \\
\text { very severe }\end{array}$ & $\begin{array}{l}0 \\
1 \\
2 \\
3\end{array}$ \\
\hline Temperature $\left({ }^{\circ} \mathrm{C}\right)$ due to colitis & $\begin{array}{l}37-38 \\
>38\end{array}$ & $\begin{array}{l}0 \\
3\end{array}$ \\
\hline Extraintestinal manifestations & $\begin{array}{l}\text { iritis } \\
\text { erythema nodosum } \\
\text { arthritis }\end{array}$ & $\begin{array}{l}3 \\
3 \\
3\end{array}$ \\
\hline Laboratory & $\begin{array}{l}\mathrm{ESR}>50 \\
\mathrm{ESR}>100 \\
\mathrm{Hb}<10 \cdot 0\end{array}$ & $\begin{array}{l}1 \\
2 \\
4\end{array}$ \\
\hline
\end{tabular}

$\mathrm{ESR}=$ erythrocyte sedimentation rate, $\mathrm{Hb}=$ haemoglobin .

in the lamina propria, 3 as crypt abscess formation and inflammation in the lamina propria, 4 as more severe inflammation with destructive crypt abscesses plus or minus granulomata, and 5 as severe inflammation with active ulceration. No patient had granulomata and the diagnosis of ulcerative colitis, excluding other inflammatory diseases, was histologically confirmed in all patients.

Tissue samples for flow cytometric analysis were submitted to mechanical disintegration and fixed in $70 \%$ ethanol for 25 minutes, after which the cells were suspended in phosphate buffered saline buffer and centrifuged at $1200 \mathrm{rpm}$. Cells were resuspended and counted at optical microscopy, with an optimal value of $500000 / 1000000$ cells $/ \mathrm{ml}$. The monolayer cells were then resuspended in a propidium iodide $(50 \mathrm{mcg} / \mathrm{ml}$, Sigma Chemicals), $0 \cdot 1 \%$ dibasic sodium citrate, $0 \cdot 1 \%$ NONIDET NP40, and RNAse $(0.5 \mathrm{ng} / \mathrm{ml}, 100 \mathrm{U}$, Sigma Chemical) solution, and incubated in the dark for 30 minutes. The suspension was then filtered through 50 micron nylon filters and analysed by a Facscan flow cytometer (Becton Dickinson), with human lymphocytes supplemented with chicken erythrocytes $1: 10$ as a reference sample (Krishan modified ${ }^{7}$ ).

$S$ phase values were calculated utilising the SOBR mathematical model, consisting in successive approximation to the actual histogram, and fitting G0/G1 and G2+M populations with single Gaussian curves: three to eight Gaussian convolute rectangles fit the $S$ phase. If the $S$ phase was not well separated from the $G 2+M$ phases or for every low $S$ phase values we applied the SFIT model, which uses a second order polynomial $\left(y=a x^{2}+b x+c\right)$ to determine the height of the $S$ phase at any channel of the FACSCAN: this model determines a region of 'pure' $S$ phase, which contains no $\mathrm{G} 0 / \mathrm{G} 1$ or $\mathrm{G} 2+M$ cells (Figs 1 and 2).

The proliferative index (PI) was calculated as the fractional number of cells with a DNA content corresponding to the synthetic ( $\mathrm{S}$ phase) and $\mathrm{G} 2+\mathrm{M}$ phases of the cell cycle.

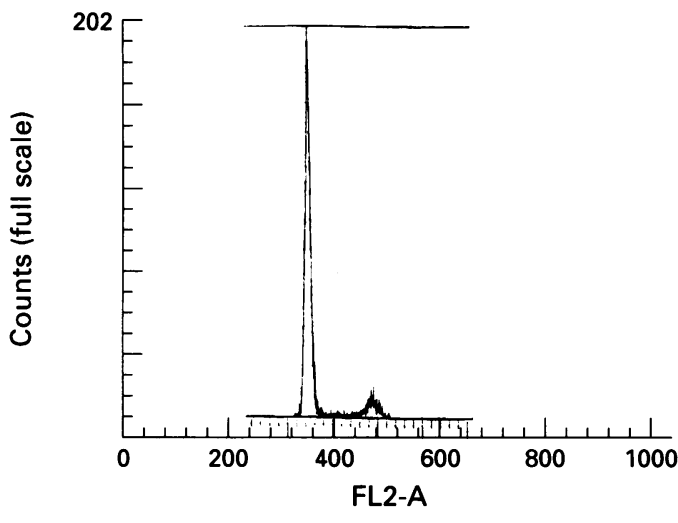

Figure 1: Example of histogram from a rectal sample: $S$ phase calculated according to SOBR model.

The mean coefficient of variation (CV) was $4 \cdot 7 \%$ (range $2 \cdot 9-6 \cdot 2 \%$ ). Lymphocyte control cells showed a mean $\mathrm{CV}$ of $2.6 \%$ (range $1 \cdot 8-3 \cdot 4 \%$ ). Lower CVs imply higher precision: CVs higher than $3 \%$ for test spheres or nuclei suggest that the apparatus requires adjustment: the instrument is ready for analysis of test samples when a low, reproducible CV is obtained for the control material. Coefficients of variation of DNA distributions from actual samples are typically higher than CVs of distributions from standards. 89

For statistical analysis we used the two tailed correlation test, analysis of variance, and regression analysis. The study complied with the standards of the ethical committee of our institution.

\section{Results}

\section{CLINICAL ACTIVITY}

The clinical assessment of illness activity varies from 1 to 9 according to the above mentioned score. For statistical evaluation we grouped the patients in grade 1 (score 1,17 patients, $28.3 \%$ ), grade 2 (scores $2-3,19$ patients, $31.6 \%$ ), grade 3 (scores $4-5,11$ patients, $18 \cdot 4 \%$ ), and grade 4 (scores $6-9,13$ patients, $21 \cdot 6 \%$ ).

\section{HISTOLOGICAL ACTIVITY}

Three patients $(5 \%)$ were grade $1,27(45 \%)$ grade 2, $21(35 \%)$ grade 3 , and $9(15 \%)$ grade 4 of histological activity.

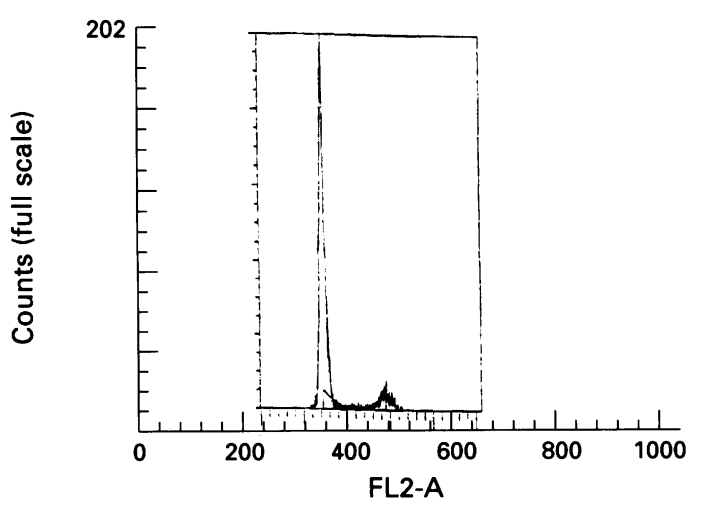

Figure 2: Example of histogram from a rectal sample: $S$ phase calculated according to SFIT model. 


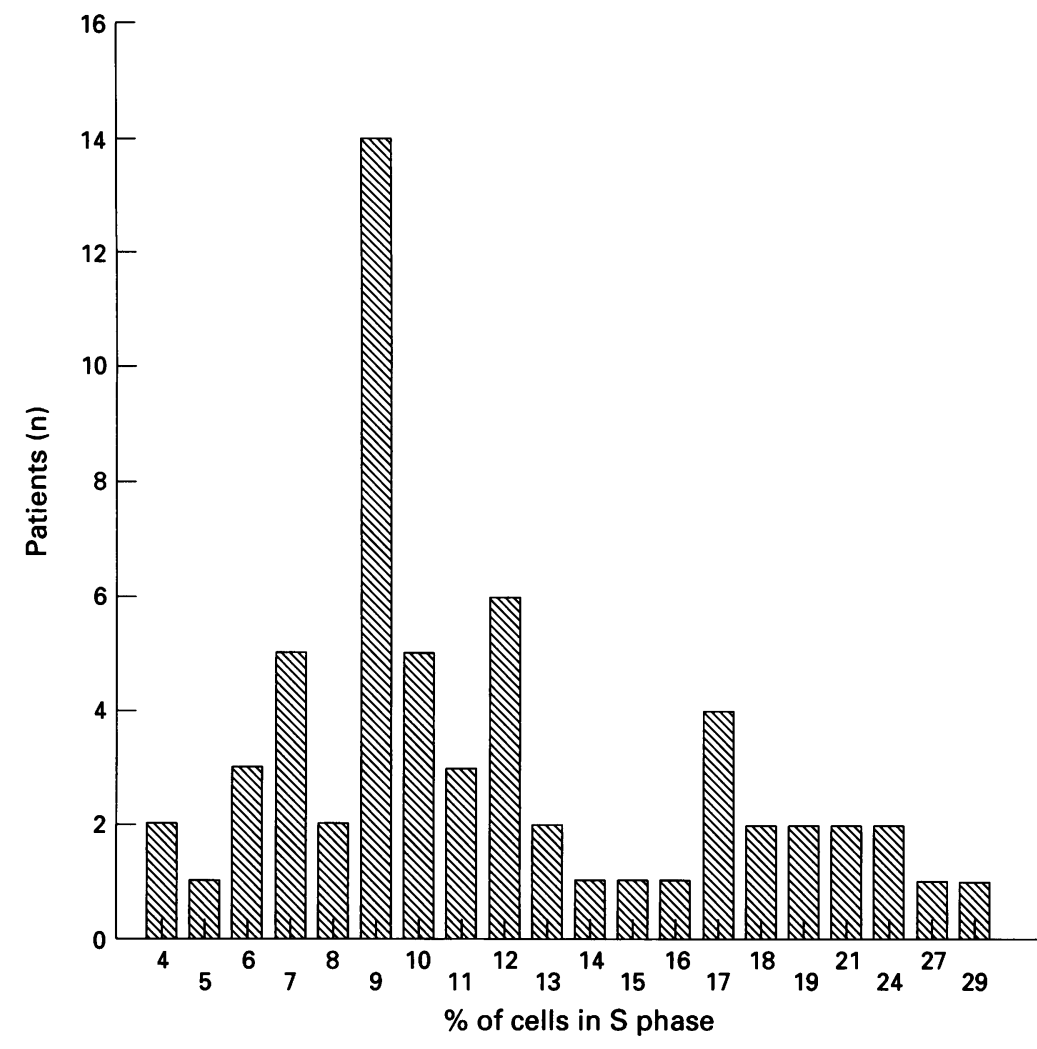

Figure 3: Distribution of synthetic phase values (expressed as percentage of the whole cell cycle).

ENDOSCOPIC ACTIVITY

As regards the endoscopic appearances of the rectal mucosa, six patients $(10 \%)$ were assigned to severity group $1,27(45 \%)$ to group 2, $15(25 \%)$ to group 3, and $12(20 \%)$ to group 4.

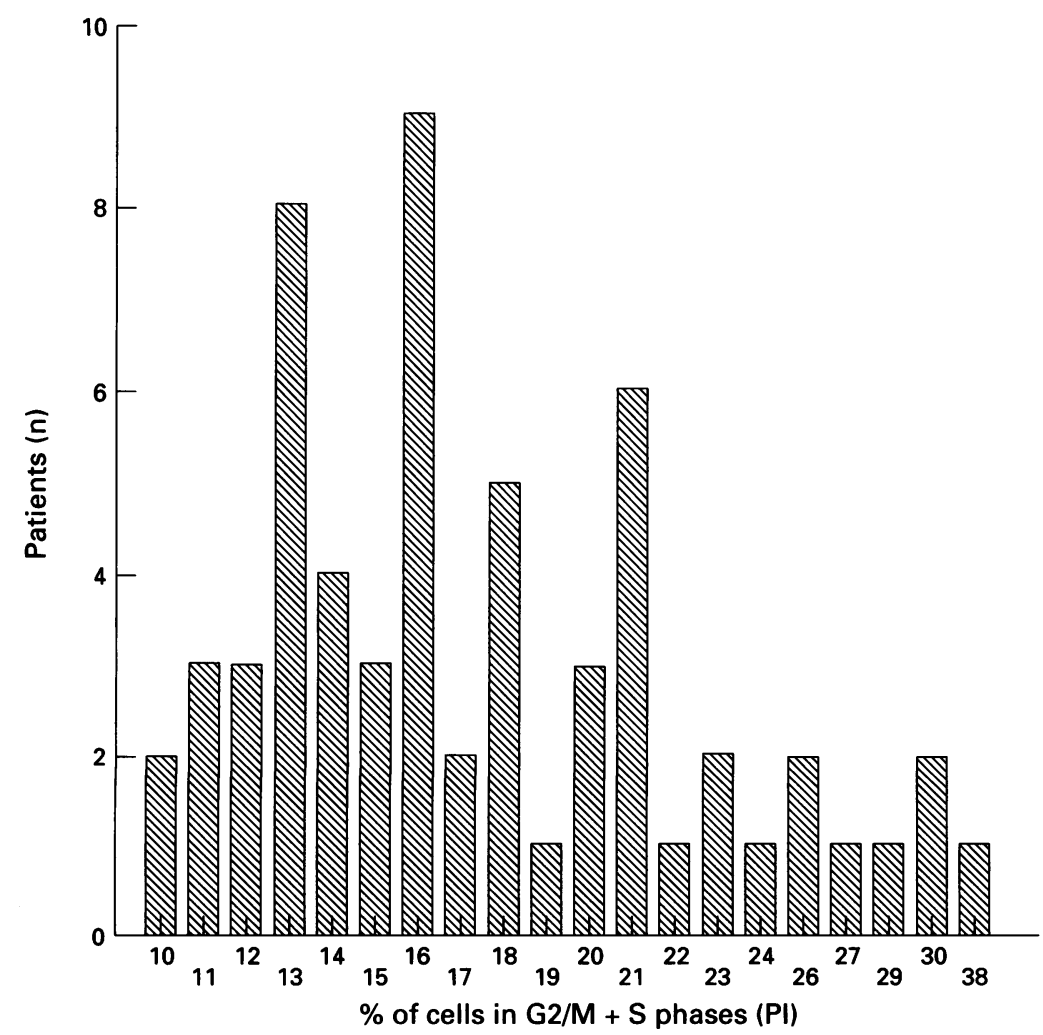

Figure 4: Distribution of proliferative index (PI) values (expressed as percentage of the whole cell cycle).

\section{FLOW CYTOMETRIC ANALYSIS}

We considered separately for statistical evaluation both the synthetic phase of the cell cycle alone and the so called proliferative index (the sum of the $S$ and $G_{2}+M$ phases of the cycle): the reported values were divided into quartiles and then submitted to analysis. $\mathrm{S}$ phase values ranged from 4 to $29 \%$ and the proliferative index from 10 to $38 \%$ (Figs 3 and 4 ).

\section{CORRELATION TESTS}

The above mentioned variables were inserted in a two tailed correlation test: we noticed a significant $(p<0.001)$ correlation between all the illness severity assessment methods considered (Table II). We also analysed the correlation between the proliferative index and the clinical, histological, and endoscopic scores calculated as a whole: a significant correlation was found $(\mathrm{p}<0.001)$ with an overall $\chi^{2}$ value of $27 \cdot 6$ with 8 degrees of freedom.

We also did the regression analysis for the mean difference in proliferative index versus global score (endoscopy plus histology plus clinical index) in the 20 patients we analysed before and after a therapeutic course with mesalazine $3.6 \mathrm{~g}$ orally. Figure 5 shows that a close correlation was detected with a coefficient of correlation $r$ of 0.71 .

\section{Discussion}

The gold standard in the routine clinical assessment of ulcerative colitis is the three step grading system by Truelove and Witts. ${ }^{1}$ This is easy to use and makes good clinical sense, but it is not wholly reliable in controlled clinical trials.

There is a critical need for a more quantitative and reproducible index for planning the management and evaluating the treatment. Several such clinical indices have been proposed, aimed at providing a numerical activity score. The Powell-Tuck activity score ${ }^{10}$ has been used in several clinical trials, but it relies heavily on symptoms and signs. Gomes et $\mathrm{al}^{6}$ devised a similar scoring system and compared it with endoscopic and histological findings, but, unfortunately, failed to establish any statistically significant correlation.

In contrast O'Morain et al ${ }^{11}$ developed an ulcerative colitis activity index, which significantly correlates with micro and macroscopic findings.

Rutegaard ${ }^{12}$ devised a compound activity index, which is the sum of three different scores for history of illness, macro and microscopic findings.

Other clinical, endoscopic, and histological scores have been proposed, all of which are quite similar, but fail to assure full inter and intraobserver reproducibility, ${ }^{13-22}$ an objection first raised by Baron ${ }^{23}$ in relation to sigmoidoscopic appearances.

As Rutegaard pointed out, ${ }^{24}$ instead of constructing a single overall index, a better solution would be the separate assessment of disease activity, as reflected by patient symptoms, and disease severity, as measured 
TABLE II Correlation test

\begin{tabular}{llllll}
\hline & Histology & S phase & $\begin{array}{l}\text { Proliferative } \\
\text { index }\end{array}$ & Endoscopy & $\begin{array}{l}\text { Clinical } \\
\text { index }\end{array}$ \\
\hline Histology & 1.0000 & $0.4596 \dagger$ & $0.4949 \dagger$ & $0.8418 \dagger$ & $0.6596 \dagger$ \\
S phase & $0.4596 \dagger$ & 1.0000 & $0.8111 \dagger$ & $0.5242 \dagger$ & $0.4989 \dagger$ \\
Proliferative index & $0.4949 \dagger$ & $0.8111 \dagger$ & 1.0000 & $0.5306 \dagger$ & $0.5493 \dagger$ \\
Endoscopy & $0.8418 \dagger$ & $0.5242 \dagger$ & $0.5306 \dagger$ & 1.0000 & $0.6878 \dagger$ \\
Clinical index & $0.6596 \dagger$ & $0.4989 \dagger$ & $0.5493 \dagger$ & $0.6878 \dagger$ & 1.0000 \\
\hline
\end{tabular}

Two tailed significance: ${ }^{\star}=0.01, \dagger=0.001$, no of cases $=60$. Numbers are expression of correlation coefficient, $(r)$.

by more objective means. A number of measures of inflammation change in relation to active disease, but it has yet to be established which biochemical variables should be used. ${ }^{25}$ Riley $^{4}$ claims that the presence and severity of histological inflammation of the mucosa is of prognostic relevance in ulcerative colitis, but the reproducibility of the data is good only in part, depending on the variables observed. At the same time Korelitz et al ${ }^{26}$ have shown that the quantitative mucosal cell count shows a significant reduction in inflammatory cells after medical treatment.

DNA flow cytometry has been validated as a valuable method of assessing abnormal cellular DNA distribution as a specific marker for malignant transformation in longstanding ulcerative colitis. ${ }^{27}$ This method may also be used in quantitating the cell cycle distribution, calculating the cells in the synthetic phase of the cycle. This proliferative activity primarily depends on the presence of mucosal acute inflammatory cells, with a very high cellular turnover. The method we used does not allow us to separate epithelial and inflammatory cells. The good correlation between histological inflammation and the values of the proliferative phases of the cell cycle may support the hypothesis that the fluctuations in the proliferative index and $S \mathrm{~F}^{\mathrm{h}}$ ? depend primarily on the amount of inflamm tory cells. No difference was noted when, , test the hypothesis of the presence of greate vroliferative activity in longstanding illn $\epsilon$, we divided the patients on the basis of the duration of their ulcerative colitis (more or less than 10 years from onset of symptoms).

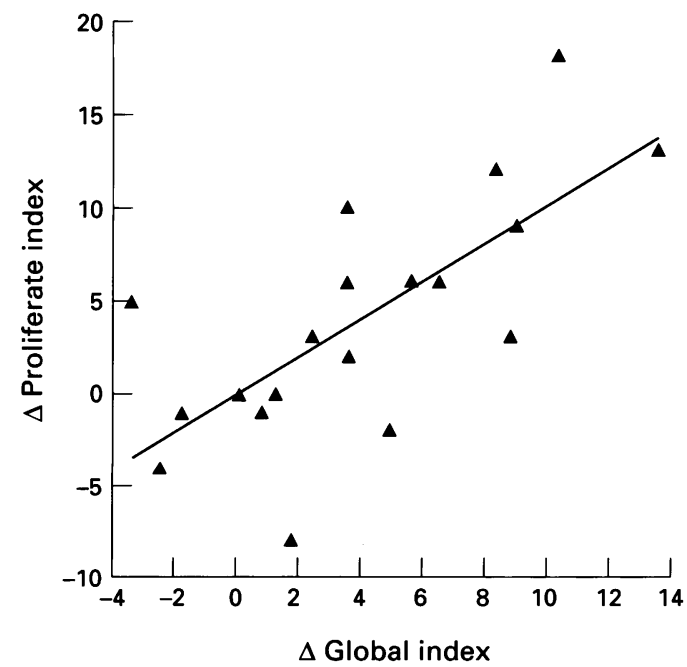

Figure 5: Relation between the mean differences in proliferative index ( $\Delta$ proliferative index) and global (histological plus endoscopic plus clinical) index ( $\Delta$ global index) values before and after medical treatment.
In our patients, a statistically significant correlation was found between flow cytometric findings and the other endoscopic, clinical, and histological indices used in assessing severity of disease. The $r$ values for the $\mathrm{S}$ phase and proliferative index values and the other variables considered are not very high, but we do not consider histological, endoscopic, or clinical indices as gold standards for this disease. Our data only suggest that a distinct correlation exists between these different indices: the relative strength of this correlation depends on the reproducibility of the indices. The aim of this study was to validate DNA flow cytometry as an objective method of measuring disease severity.

Calculation of S phase is not always uncomplicated, depending on an incomplete separation of cells in the different phases of the cycle and on the presence of a light background fluorescence resulting from cellular fragments. A number of adequate mathematical models have to be applied both to distinctly analyse the cellular cycle in every situation and to significantly reduce background values. We applied the SFIT model (a second order polynomial) to calculate $S$ phase values when the $S$ phase was not well separated from the $\mathrm{G} 2+\mathrm{M}$ ones, or for very low $S$ phase values, or when the G0/G1 coefficient of variation was less than $5 \%$. For higher coefficients of variation, it might be a risk of overestimating the $\mathrm{G} 0 / \mathrm{G} 1$ phases and underestimating the $\mathrm{G} 2+\mathrm{M}$ ones: in these cases we used the SOBR model, as successive approximations to the actual histogram, fitting G0/G1 and $G 2+M$ populations with single Gaussian curves. The values obtained with the two different methods in skilled hands were fully compatible and with good agreement. It might sometimes be the case of two significatively different values obtained with the two models: in these cases we calculated the mean $S$ phase value between the two, aiming at reducing a mathematical under or overestimation of data.

We considered the rectal segment representative of disease activity, as did Fochios in his study. ${ }^{28}$ Unpublished results with samples taken elsewhere in the colon in the same patients closely resemble the rectal findings as far as severity of disease is concerned, allowing us to consider rectal mucosa (that we can anyway easily reach) as representative of the whole inflamed colonic mucosa. Holmqvist et $a l^{29}$ reported different results in a paediatric population, with a lower degree of inflammation in the rectum than in the colon in about one third of patients with ulcerative colitis, but this seemed to depend on the use of corticosteroid rectal enemas in almost all cases.

We are now validating our data in a prospective controlled trial by means of DNA flow cytometric determinations on samples of rectal mucosa before and after medical treatment. The preliminary results are quite encouraging, showing a good correlation between severity of disease and the proliferative index of the rectal mucosa: in 20 patients we found a significant correlation between the examined variables, with a good coefficient of correlation $r$. 
The advantage of DNA flow cytometry on the conventional tests is mainly in its accuracy, low inter and intraobserver variability, and reproducibility of data. It analyses a much greater number of cells (about $10000 v 300$ ) in a much shorter period of time (few seconds $v$ roughly 15 minutes) than a routine histological examination. On the other hand, it gives only quantitative and not qualitative data. We therefore suggest its use in controlled trials to obtain reproducible and comparable results, and currently as a complement to routine histological tests in clinical use: problems of costs and availability of the flow cytometer may in fact limit its use in a number of institutions.

In conclusion, we suggest that DNA flow cytometry, in addition to providing information on DNA aneuploidy as a precancerous lesion, may also afford a reproducible and efficient method for evaluating severity of disease and efficacy of medical treatment in ulcerative colitis.

1 Truelove SC, Witts LJ. Cortisone in ulcerative colitis. Final report on a therapeutic trial. $B M 7$ 1955: 2: 1041-8.

2 Kjeldsen J, Schaffalitzky de Muckadell OB. Assessment of disease severity and activity in inflammatory bowel disease severity and activity in inflammato

3 Borkie B, Hostmark J, Skagen DW, Schrumpf E, Laerum OD. Flow cytometry of biopsy specimens from ulcerative colitis, colorectal adenomas and carcinomas. Scand $\mathcal{f}$ Gastroenterol 1987; 22: 1231-7.

4 Riley SA, Mani V, Goodman MJ, Dutt S, Herd ME. Microscopic activity in ulcerative colitis: what does it mean? Gut 1991; 32: 174-8.

5 Rachmilewitz D. Coated mesalazine (5-aminosalicylic acid) versus sulphasalazine in the treatment of active ulcerative colitis: a randomised trial. $B M \mathcal{F} 1989$; 298: 82-6.

6 Gomes P, Du Boulay C, Smith CL, Holdstock G. Relationship between disease activity indices and colonoscopic findings in patients with colonic inflammatory bowel disease. Gut 1986; 27: 92-5.

7 Krishan A. Rapid flow cytofluorometric analysis of mammalian cell cycle by propidium iodide staining. $\mathcal{F}$ Cell Biol malian cell cycle by

8 Shapiro HM. Flow cytometry of DNA content and other indicators of proliferative activity. Arch Pathol Lab Med indicators of prolifer

9 McCarthy RC, Fetterhoff TJ. Issues for quality assurance in clinical flow cytometry. Arch Pathol Lab Med 1989; 113: 658-66.

10 Powell-Tuck J, Bown RL, Lennard-Jones JE. A comparison of oral prednisolone given as single or multiple daily doses for active proctocolitis. Scand $\mathcal{F}$ Gastroenterol 1978; 13: 833-7.
11 O'Morain C, Tobin A, Leen E, Suzuki Y, O'Riordan T. Criteria of case definition in Crohn's disease and ulcerative colitis. Scand $\mathcal{F}$ Gastroenteral 1989; 24 (suppl 170): 7-11.

12 Rutegard J, Jorgen R, Lars A, Roger S, Tornbjorn N. A simple index for assessment of disease activity in patients with ulcerative colitis. Hepatogastroenterology 1990; 37 (suppl II): 110-2.

13 Schroeder $\mathrm{KW}$, Tremaine WJ, Ilstrup DM. Coated oral 5-aminosalicylic acid therapy for mildly to moderately active ulcerative colitis. $N$ Engl f Med 1987; 317: 1625-9.

14 Sutherland LR, Martin F, Greer S, Robinson M, Greenberger N, Saibil F, et al. 5-aminosalicylic acid enema in the treatment of distal ulcerative colitis, proctosigmoiditis, and proctitis. Gastroenterology 1987; 92: 1894-8.

15 Pera A, Bellando P, Caldera D, Ponti V, Astegiano M, Barletti C, et al. Colonoscopy in inflammatory bowel disease. Gastroenterology 1987; 92: 181-5.

16 Riley SA, Mani V, Goodman MJ, Herd ME, Dutt S, Turnberg LA. Comparison of delayed-release 5aminosalicylic acid (mesalazine) and sulfasalazine as maintenance treatment for patients with ulcerative colitis. Gastroenterology 1988: 94: 1383-9.

17 Riley SA, Mani V, Goodman MJ, Herd ME, Dutt S, Turnberg LA. Comparison of delayed release 5 aminosalicylic acid (mesalazine) and sulphasalazine in the treatment of mild to moderate ulcerative colitis relapse. Gut 1988; 29: 669-74.

18 Lichtiger S, Present DH. Preliminary report: cyclosporin in treatment of severe active ulcerative colitis. Lancet 1990; 336: 16-9.

19 Sninsky CA, Cort DH, Shanahan F, Powers BJ, Sessions JT, Pruitt RE, et al. Oral mesalamine (Asacol) for mildly to moderately active ulcerative colitis. A multicenter study. Ann Intern Med 1991; 115: 350-5.

20 Campieri M, Gionchetti P, Belluzzi A, Brignola C, Tampieri $M$, Iannone $P$, et al. Optimum dosage of 5 -aminosalicylic acid as rectal enemas in patients with 5-aminosalicylic acid as rectal enemas in patien

21 Aslan A, Triadafilopoulos G. Fish oil fatty acid supplementation in active ulcerative colitis: a double-blind, placebotation in active ulcerative colitis: a double-blind, placebocontrolled.

22 Seo $M$, Okada $M$, Yao T, Ueki M, Arima $S$, Okumura $M$. An index of disease activity in patients with ulcerative colitis. Am f Gastroenterol 1992; 87: 971-6.

23 Baron JH, Connell AM, Lennard-Jones JE. Variation between observers in describing mucosal appearances in proctocolitis. $B M \Im$ 1964; 1: 89-92.

24 Rutegard JN. Assessment profiles of disease severity in ulcerative colitis. Dig Dis 1993; 11: 32-5.

25 Beck IT. Laboratory assessment of inflammatory bowel disease. Dig Dis Sci 1987; 32 (suppl 12): 26-41S.

26 Korelitz BI, Sommers SC. Responses to drug therapy in ulcerative colitis. Evaluation by rectal biopsy and histopathological changes. Am f Gastroenterol 1975; 64: 365-70.

27 Hammarberg C, Slezak P, Tribukait B. Early detection of malignancy in ulcerative colitis. A flow-cytometric DNA study. Cancer 1984; 53: 291-5.

28 Fochios SE, Korelitz BI. The role of sigmoidoscopy and rectal biopsy in diagnosis and management of inflammatory bowel disease: personal experience. $\mathrm{Am} \mathfrak{J}$ Gastroenterol 1988; 83: 114-9.

29 Holmquist L, Ahren C, Fallstrom SP. Clinical disease activity and inflammatory activity in the rectum in relation to mucosal inflammation assessed by colonoscopy. Acta Paediatr Scand 1990; 79: 527-34. 